\title{
Diagnostic Modalities in Multiple Sclerosis: Perspectives in Children
}

\author{
I-Jun Chou ${ }^{1-4}$, William P Whitehouse ${ }^{4,5}$, Huei-Shyong Wang ${ }^{1}$, Radu Tanasescu $^{3,6}$, Cris S Constantinescu $^{3}$
}

Pediatric multiple sclerosis (MS) represents only $2-5 \%$ of the MS population, but children with MS have a higher relapse rate and reach permanent disability at a younger age than adult-onset MS. Early and accurate diagnosis of pediatric MS is vital for prompt treatment to mitigate ongoing neuroinflammation and irreversible neurodegeneration. However, it is difficult to differentiate MS from acute disseminated encephalomyelitis (ADEM) and neuromyelitis optica (NMO) in pediatric patients, even considering the clinical, magnetic resonance imaging (MRI), and paraclinical findings, because the first presentation of inflammatory demyelination in children is often atypical. The purpose of this review is to summarize the clinical, neuroimaging, and paraclinical key differences between pediatric patients with MS,

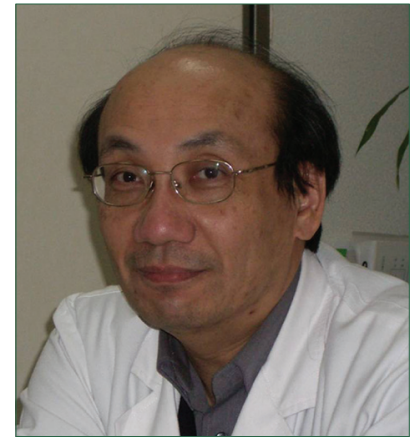

Dr. Huei-Shyong Wang ADEM, and NMO and to discuss novel biomarkers, such as antibodies to aquaporin-4 (AQP4) and myelin oligodendrocyte glycoprotein (MOG), which may help in making a diagnosis. (Biomed J 2014;37:50-59) Key words: acute disseminated encephalomyelitis, aquaporin-4, magnetic resonance imaging,
myelin oligodendrocyte glycoprotein, neuromyelitis optica

$\mathrm{M}$ ultiple sclerosis (MS) is a chronic debilitating disease with a pathological hallmark of inflammatory demyelination in the white matter and cortex, implying a disturbance of the symbiotic relationship of the axon and myelin sheath. ${ }^{[1]}$ It is an immune-mediated disease involving the brain, spinal cord, and the optic nerves. The onset of MS generally occurs at the age of 30, but approximately $2-5 \%$ of MS patients have disease onset at an age younger than 16 years. ${ }^{[2-4]}$ More than $85 \%$ of adult-onset patients experience a relapsing-remitting multiple sclerosis (RRMS) course and $10 \%$ have a primary progressive onset with no or only a single acute event. ${ }^{[5]}$ In contrast, the RRMS course comprises more than $98 \%$ of pediatric-onset MS. ${ }^{[2-4,6]}$

The overall prognosis of pediatric-onset MS tends to be worse than adult-onset MS, with a higher relapse rate $^{[7]}$ and a higher magnetic resonance imaging (MRI) lesion burden. ${ }^{[8]}$ Pediatric-onset MS patients often develop fixed disability on average two decades after diagnosis, and their median age at evolution to secondary progression and reaching the fixed disability milestone is about 10 years younger than that of adult-onset patients. ${ }^{[2,3]}$ In addition, the social and individual impact and cost of the disease in pediatric MS patients is significantly higher. For example, cognitive dysfunction is found in about $30 \%$ of pediatric MS children and adolescents, and more than half of them have at least one psychiatric diagnosis. ${ }^{[9,10]}$ These complications impair learning and the chance of sustained employment. Pediatric MS, therefore, comprises a small but important subgroup of MS, in whom the diagnosis must be differentiated from clinical mimics such as acute dis-

From the ${ }^{1}$ Division of Pediatric Neurology, Chang Gung Children's Hospital at Linkou, Chang Gung University College of Medicine, Taoyuan, Taiwan; ${ }^{2}$ Division of Pediatric General Medicine, Chang Gung Children's Hospital at Linkou, Chang Gung University College of Medicine, Taoyuan, Taiwan; ${ }^{3}$ Division of Clinical Neuroscience, School of Medicine, University of Nottingham, Nottingham, England, UK; ${ }^{4}$ Division of Child Health, Obstetrics and Gynaecology, School of Medicine, University of Nottingham, Nottingham, England, UK; ${ }^{5}$ Department of Paediatric Neurology, Nottingham Children's Hospital, Nottingham University Hospitals Trust, Nottingham, Nottinghamshire, England, UK; ${ }^{6}$ Department of Neurology, Colentina Hospital, Carol Davila University of Medicine and Pharmacy, Bucharest, Romania Received: Dec. 02, 2013; Accepted: Feb. 26, 2014

Correspondence to: Dr. Huei-Shyong Wang, Division of Pediatric Neurology, Department of Pediatrics, Chang Gung Children's Hospital at Linkou. 5 Fusing St., Gueishan, Taoyuan 333, Taiwan (R.O.C). Tel: 886-3-3281200 ext. 8212; Fax: 886-3-3288957; E-mail: wanghs444@ cgmh.org.tw

DOI: $10.4103 / 2319-4170.129269$ 
seminated encephalomyelitis (ADEM) and neuromyelitis optica (NMO).

The distinction of MS, ADEM, and NMO is important for considerations of prognosis and treatment. The long-term treatments differ for MS (immunomodulation: First-line with interferon- $\beta$ or glatiramer acetate ${ }^{[11]}$ and second-line with natalizumab ${ }^{[11-15]}$ or rarely cyclophosphamide ${ }^{[11,16]}$ ) and NMO (immunosuppression with azathioprine ${ }^{[17-20]}$ or mycophenolate ${ }^{[20,21]}$ or B-cell depletion therapy with rituximab $\left.^{[20-24]}\right)$. In addition, immunomodulatory agents such as interferon- $\beta$ may cause exacerbation in patients with NMO. ${ }^{[25,26]}$ Patients with ADEM do not need long-term treatments because it is typically a single acute event; ${ }^{[27]}$ however, they sometimes need prolonged steroid treatment.

In this review, we summarize the clinical, neuroimaging, and paraclinical key differences between pediatric patients with MS, ADEM, and NMO, and review the biomarkers that facilitate diagnosis and may aid decision making of management.

\section{Pathogenesis}

The pathogenesis of pediatric MS is complex. Current evidence suggests that the disease might arise from interactions between immune systems and environmental factors (e.g. Epstein-Barr virus infection, smoking) and partly depends on the individual susceptibility [e.g. human leukocyte antigen (HLA) gene, vitamin D deficiency]. ${ }^{[28-31]}$ These complex interactions are supported by a cohort study comprising 302 children with a first inflammatory demyelinating episode, which found that children with all three risk factors (remote Epstein-Barr virus infection, low serum 25-hydroxyvitamin D concentrations, presence of HLA-DRB $1 * 15$ alleles) were more likely to have a diagnosis of MS eventually than those with no or only one risk factor. $^{[32]}$

\section{Epidemiology}

The incidence of acquired inflammatory demyelinating syndromes of the central nervous system (CNS) has been estimated to be $0.6-1.66 / 100,000$ children per year, ${ }^{[33-36]}$ and a quarter to a third of them eventually are diagnosed with MS. ${ }^{[32,34,37]}$ About $80 \%$ of pediatric-onset MS patients had a first acquired inflammatory demyelinating syndrome onset at over 10 years of age. ${ }^{[38]}$ The initial presentation of pediatric-onset MS can be with polyfocal clinically isolated syndrome (CIS) (26-66\%), optic neuritis (ON; 10-23\%; more commonly bilateral involvement), isolated acute transverse myelitis (TM; 2-14\%), or ADEM (8-18\%). ${ }^{[3,40]}$ Bilateral sequential or recurrent $\mathrm{ON}$ with an abnormal brain MRI is associated with an increased risk of MS in children. ${ }^{[41]}$ In addition, an inter-attack interval shorter than 1 year, multiple relapses in the first 2 years of the disease, or a higher number of relapses increased the risk of developing a secondary progressive MS..$^{[42]}$

\section{Diagnostic consensus}

The diagnosis of MS in both adults and children is evolving, but the early diagnosis in children is still a challenge because the initial presentation of acute CNS inflammatory demyelination is usually atypical. Two other major mimics of MS are ADEM and NMO; both are more common in pediatric populations than in adults and have different treatment strategies. The first consensus definition for pediatric MS and related disorders for patients younger than 18 years of age was published in $2007^{[43]}$ and later revised in $2013^{[27]}$ by the International Pediatric Multiple Sclerosis Study Group (IPMSSG). Table 1 shows the main criteria used currently for diagnosing CIS, ADEM, and NMO. Table 2 summarizes the diagnostic requirements for pediatric MS; each row constitutes a separate case definition for MS. The MRI criteria for pediatric MS diagnosis should apply the updated 2010 revised McDonald criteria ${ }^{[44]}$ and are detailed in Table 3.

\section{The clinical CNS event}

The first event of acquired inflammatory demyelinating syndromes is defined as a single acute-onset CNS event caused by presumed inflammatory demyelination in a previously healthy and developmentally intact child without any clinical history of symptoms of CNS demyelination. The symptom must last at least $24 \mathrm{~h}$ and the diagnosis must have "no better explanation" than inflammatory demyelination. For instance, leptomeningeal enhancement suggests a vasculitic or malignant process ${ }^{[45]}$ and any previous insidious or progressive pattern of onset suggests an inheritable white matter disease. ${ }^{[46]}$ After the first attack, the second or MS-defining event is typically within 2 years. ${ }^{[47]}$ If the first event is bilateral $\mathrm{ON}, 36 \%$ of pediatric cases develop MS within 2 years. ${ }^{[48,49]}$

\section{Clinically isolated syndrome}

The term "clinically isolated syndrome" is used to define the first CNS event suggestive of inflammatory demyelination, but which does not fulfil the diagnosis of ADEM, NMO, or MS. ${ }^{[50,51]}$ The CIS can be either monofocal or polyfocal without encephalopathy. The presentation is heterogeneous involving optic nerve, spinal cord, brain stem, cerebellum, and any parts of the supratentorial brain.

\section{Acute disseminated encephalomyelitis}

ADEM presents with a polyfocal clinical index event with encephalopathy and an abnormal brain MRI within 3 months of the onset. Typically, the MRI shows diffuse, poorly demarcated, bilateral but usually asymmetrical T2-hyperintense lesions lager than 1-2 cm. T1-weighted 
Table 1: Diagnostic consensus for pediatric clinically isolated syndrome, acute disseminated encephalomyelitis, and neuromyelitis optica $^{[27]}$

\begin{tabular}{ll}
\hline All are required & Variants \\
\hline CIS & \\
A first monofocal or polyfocal CNS event with presumed inflammatory demyelinating cause & \\
Absence of a prior clinical history of CNS demyelinating disease (e.g. absence of past ON, & \\
TM, hemispheric or brain-stem syndromes) & \\
No encephalopathy that cannot be explained by fever & Multiphasic ADEM \\
The baseline MRI does not meet the diagnostic criteria for MS & Two events consistent with ADEM attacks \\
ADEM & separated by $\geq 3$ months \\
A first polyfocal clinical CNS event with presumed inflammatory demyelinating cause & \\
Encephalopathy that cannot be explained by fever & \\
No new clinical and MRI findings emerge $\geq 3$ months after the onset & \\
Brain MRI is abnormal during the acute phase (<3 months) & \\
Typical brain MRI findings: & \\
Diffuse, poorly demarcated, $>1-2$ cm lesions involving mainly the cerebral white matter & NMO spectrum disease \\
"Rare" T1-hypointense lesions in the white matter & Relapsing ON with positive serum anti- \\
Deep gray matter lesions can be present & AQP4-IgG \\
NMO & Relapsing TM with positive serum anti- \\
ON & AQP4-IgG \\
Acute TM & \\
$\geq 2$ of three supportive criteria & \\
Contiguous long extended spinal cord lesion $\geq 3$ vertebral segments & \\
Brain MRI does not meet the diagnostic criteria for MS & \\
Positive serum anti-AQP4-IgG & \\
\hline Abbrition &
\end{tabular}

Abbreviations: CNS: Central nervous system; ON: Optic neuritis; TM: Transverse myelitis; MRI: Magnetic resonance imaging; IgG: Immunoglobulin G; ADEM: Acute disseminated encephalomyelitis; NMO: Neuromyelitis optica; MS: Multiple sclerosis

Table 2: Diagnostic consensus for pediatric multiple sclerosis (each row constitutes a separate case definition for MS) ${ }^{[27]}$

\begin{tabular}{|c|c|c|c|c|c|c|c|c|}
\hline \multirow{2}{*}{$\begin{array}{l}\text { Number of clinical } \\
\text { CNS events with } \\
\text { presumed inflammatory } \\
\text { demyelinating cause }\end{array}$} & \multirow{2}{*}{$\begin{array}{l}\text { Patient } \\
\text { age } \\
\text { (years) }\end{array}$} & \multirow{2}{*}{$\begin{array}{l}\text { No. of } \\
\text { MRI } \\
\text { scans }\end{array}$} & \multirow{2}{*}{$\begin{array}{l}1^{\text {st }} \text { clinical } \\
\text { CNS event }\end{array}$} & \multirow[t]{2}{*}{ Time gap } & \multirow{2}{*}{$\begin{array}{l}2^{\text {nd }} \text { clinical CNS } \\
\text { event }\end{array}$} & \multicolumn{3}{|c|}{ MRI requirements } \\
\hline & & & & & & $\begin{array}{l}\text { Dissemination } \\
\text { in space* }\end{array}$ & $\begin{array}{l}\text { Dissemination } \\
\text { in time* }\end{array}$ & Note \\
\hline$\geq 1$ & $\geq 12$ & $\geq 1$ & Non- & & & Yes & Yes & \\
\hline$\geq 1$ & $<12$ & $\geq 2$ & $\begin{array}{l}\text { encephalopathic } \\
\text { episode }\end{array}$ & & & Yes & Yes & $\begin{array}{l}2^{\text {nd }} \text { MRI scan } \\
\text { showed } \geq 1 \text { new lesion }\end{array}$ \\
\hline$\geq 2$ & $<18$ & $\geq 1$ & & $>30$ days & $\begin{array}{l}\text { Non-encephalopathic } \\
\text { episode }\end{array}$ & & & $\begin{array}{l}\text { Involving } \geq 2 \text { areas of } \\
\text { the CNS }\end{array}$ \\
\hline$\geq 2$ & $<18$ & $\geq 2$ & ADEM & $\geq 3$ months & $\begin{array}{l}\text { Non-encephalopathic } \\
\text { episode }\end{array}$ & Yes & & $\begin{array}{l}\text { MRI scan of event } 2 \\
\text { showed new lesions } \\
\text { fulfilled DIS }\end{array}$ \\
\hline
\end{tabular}

Abbreviations: *: DIS and DIT should apply the updated 2010 revised McDonald criteria ${ }^{[44]}$; MS: Multiple sclerosis; CNS: Central nervous system; MRI: Magnetic resonance imaging; DIS: Dissemination in space; DIT: Dissemination in time; ADEM: Acute disseminated encephalomyelitis

Table 3: McDonald MRI criteria for multiple sclerosis ${ }^{[44]}$

\begin{tabular}{lclll}
\hline Dissemination in space & \multicolumn{2}{c}{ Dissemination in time } \\
\cline { 2 - 5 } & $\begin{array}{c}\text { No. of } \\
\text { MRI scans }\end{array}$ & $\begin{array}{l}\text { Time point of } \\
\text { scans }\end{array}$ & $\begin{array}{l}\text { Contrast agents } \\
\text { requirement }\end{array}$ & MRI findings \\
\hline $\begin{array}{l}\text { Asymptomatic lesions* found } \\
\begin{array}{l}\text { in the following } \geq 2 \text { of } 4 \\
\geq 1 \text { Periventricular }\end{array}\end{array}$ & 1 & At any time point & Yes & $\begin{array}{l}\text { Simultaneous presence of asymptomatic } \\
\text { gadolinium-enhancing }{ }^{\dagger} \text { and non-enhancing lesions }\end{array}$ \\
$\begin{array}{l}\geq \text { Juxtacortical } \\
\geq 1 \text { Infratentorial }\end{array}$ & 2 & At any time point & No & Scan 2 compared to scan 1 showed $\geq 1$ new T2 lesion \\
$\geq 1$ Spinal cord & & & Yes & $\begin{array}{l}\text { Scan 2 compared to scan 1 showed } \geq 1 \\
\text { gadolinium-enhancing lesion }\end{array}$ \\
\hline
\end{tabular}

Abbreviations: *: In cases of brain stem and spinal cord syndromes, all lesions within the symptomatic region were excluded ${ }^{[53]}$;

${ }^{\dagger}$ : Gadolinium-enhancing lesion should be reliably determined not due to non-MS pathology; DIS: Dissemination in space; DIT: Dissemination in time; MRI: Magnetic resonance imaging

Biomed J Vol. 37 No. 2

March - April 2014 
hypointense lesion in the white matter is rare. Patients are designated as having multiphasic ADEM if they have a second episode consistent with ADEM occurring more than 3 months after the index event. If the third episode occurs, with or without encephalopathy, it is no longer "ADEM" but should be considered another clinical entity with chronicity, such as MS or NMO.$^{[27]}$ ADEM was classified as monophasic, recurrent, and multiphasic types in previous consensus, ${ }^{[43]}$ but the current version eliminates the term "recurrent ADEM". ${ }^{[27]}$

\section{Multiple sclerosis}

The diagnosis of clinical definite MS requires two clinical events separated by at least 1 month: Evidence of dissemination in time (DIT) and clinical and paraclinical (neurophysiology or neuroimaging) evidence for the lesions exhibiting dissemination in space (DIS), and exclusion of alternative diagnoses. ${ }^{[52]}$ MRI is the most powerful paraclinical method to demonstrate both DIT and DIS, even with only one baseline MRI at the first event. ${ }^{[44]}$ It is of note that MRI evidence of both DIS and DIT is specific for MS, especially for young adults with typical CIS presentations (unilateral ON, myelitis, and brainstem syndromes). ${ }^{[53]}$

In pediatric patients with two clinical events, the first event can be CIS followed by another non-encephalopathic attack separated by more than 30 days or ADEM followed by a non-encephalopathic event separated by at least 3 months with clinical or MRI demonstrated DIS. ${ }^{[27]}$ In adolescents aged 12 years and above, a first, single, CNS non-encephalopathic event with an MRI showing evidence for both the DIS and DIT can also make the diagnosis of MS. For those aged less than 12 years, a first, single, CNS non-encephalopathic event with MRI asymptomatic lesions fulfilling DIS will need a second MRI showing at least one new lesion consistent with DIT to make the diagnosis of MS.

\section{Neuromyelitis optica}

NMO is defined as both ON and TM occurring simultaneously or sequentially with at least two of three pieces of supportive features: (1) A contiguous spinal cord MRI lesion extending over three or more vertebral segments, (2) brain MRI not meeting the diagnostic criteria for MS, ${ }^{[44]}$ and (3) the presence of anti-aquaporin-4 (AQP4) IgG in serum..$^{[27,54]}$

\section{Encephalopathy}

Encephalopathy is defined as an alteration in consciousness or a behavioral change unexplained by fever, systemic illness, or postictal epileptic symptoms. Encephalopathy, although still primarily a clinical diagnosis, was given a clearer definition in the current guideline than in the 2007 version. ${ }^{[27,43]}$ However, change of consciousness is not very specific to distinguish ADEM from MS, and it can also occur in NMO. ${ }^{[55]}$
An alteration of consciousness can also occur in adult CIS patients, initially diagnosed with ADEM. ${ }^{[56]}$ As encephalopathy is crucial in the differential diagnosis of MS, especially in those aged 12 years and above, paraclinical studies such as electroencephalograph (EEG) showing an excess of background slow wave activity ${ }^{[57]}$ may be used acutely to provide clearer evidence for or against the presence of encephalopathy.

\section{Diagnostic modalities}

The diagnosis of ADEM, NMO, CIS, and MS is based on the clinical presentations and paraclinical investigations. The most often deployed paraclinical tests are MRI, cerebrospinal fluid (CSF) examination, serum tests, and biopsy.

\section{Magnetic resonance imaging}

The characteristic morphological findings of brain MRI in MS are useful to help differentiate MS from ADEM and NMO in children. First, the presence of "Dawson's nger" which represents a lesion perpendicular to the long axis of the corpus callosum can predict the conversion to MS in children with high specificity. ${ }^{[37]}$ It is also helpful to differentiate between NMO and MS. ${ }^{[58]}$ Second, the presence of "black holes," suggesting longstanding tissue destruction, is specific for MS and is rarely visible in ADEM. ${ }^{[59,60]}$ The imaging features of "black holes" are non-enhancing hypointensity on T1 and hyperintensity on T2 imaging lasting for more than 3 months. The presence of at least one black hole lesion and at least one periventricular white matter T2-hyperintense lesion abutting any portion of the lateral ventricles predicts progression to MS in children at the first acquired inflammatory demyelinating episode. ${ }^{[60]}$ In addition, the MRI features of spinal cord lesions in MS patients are single or multiple focal, sharply delineated, T2-hyperintense lesions extending one vertebra (maximum two segments) in length; ${ }^{[61,62]}$ however, a lesion over three or more segments can also be found in pediatric-onset MS, ${ }^{[63]}$ as well as in NMO and ADEM. ${ }^{[64]}$

The specific locations of some MRI lesions, accompanied by certain clinical symptoms, are important clues suggesting NMO rather than MS. The fluid-attenuated inversion recovery (FLAIR) signal abnormality in NMO is typically contiguous throughout the periventricular and along the third or fourth ventricular periependymal tissues, and involves the hypothalamus. ${ }^{[65]}$ Besides, a linear medullary or medullospinal lesion in an individual manifesting intractable hiccups and nausea lasting more than $48 \mathrm{~h}$ are typical for NMO and extremely rare in MS. ${ }^{[66]}$

\section{Cerebrospinal fluid}

CSF is obtained for three main purposes: (1) To confirm the diagnosis of MS [e.g. presence of oligoclonal bands (OCBs)]; (2) to identify other treatable dis- 
eases (e.g. infection, systemic inflammatory disease, or tumors); and (3) to detect biomarkers, for prognosis. CSF findings supporting CNS inflammatory demyelination include an elevated immunoglobulin $\mathrm{G}(\mathrm{IgG})$ index, or at least two OCBs in the CSF but not in the corresponding serum samples ${ }^{[44]}$ on isoelectric focusing (IEF).$^{[67,68]}$ Although new diagnostic criteria for RRMS no longer require routine CSF studies, complete CSF studies are still valuable in children. In particular, a negative OCB test often prompts the consideration of other diseases mimicking MS or CIS. In children with $\mathrm{ON}$, the presence of OCBs, with or without abnormal brain MRI, has been shown to be associated with subsequent MS development. ${ }^{\left[{ }^{[9]}\right.}$ However, OCBs do not always occur in MS (85-90\%), and can present in ADEM (in up to 29\%) ${ }^{[70,71]}$ and $\mathrm{NMO}$ (in up to $30 \%$ ). ${ }^{[72]}$ In addition, if intrathecal $\mathrm{IgG}$ synthesis was detected, it tends to disappear in the ADEM and NMO patients while it is persistently detectable in MS patients.

\section{Serum autoantibodies}

Existing criteria are useful in everyday practice, but diagnostic uncertainty is frequent in pediatric inflammatory demyelinating diseases. For instance, diffuse, large, poorly demarcated T2-hyperintense brain white matter lesions can be found in the children with ADEM and NMO, ${ }^{[55,73,74]}$ and therefore, these findings alone are not concrete evidence for a specific diagnosis. Biomarkers are clinically useful for differentiating difficult cases and for disease course prediction. They are relatively non-invasive, more accessible, and may reflect biochemical or immune mechanisms. Currently, clinically relevant biomarkers include autoantibodies against AQP4 and possibly myelin oligodendrocyte glycoprotein (MOG). They may increase the confidence of disease diagnosis and facilitate decision making for long-term treatment.

\section{NMO-IgG and anti-AQP4-IgG antibody}

Anti-AQP4-IgG is the first clinically useful antibody in human inflammatory demyelinating diseases. In 1999, Wingerchuk et al. defined NMO as comprising both $\mathrm{ON}$ and TM with a long spinal cord lesion (three or more vertebral segments). ${ }^{[75]}$ From sera of 124 clinically ascertained NMO patients, NMO-IgG outlining CNS microvessels, pia, subpia, and Virchow-Robin spaces was identified. ${ }^{[76]}$ It is detectable in $60-90 \%$ of patients with NMO and is specific for NMO because the seroprevalence of this antibody in other inflammatory demyelinating diseases, including MS, is very low. The main target antigen of NMO-IgG is the astrocyte water channel protein $\mathrm{AQP} 4 .{ }^{[77]} \mathrm{AQP} 4$ is concentrated at the end-feet of astrocytes facing the blood-brain barrier (BBB), forming an integral part of the BBB and the blood-CSF barrier. ${ }^{[78-80]}$ The presence of NMO-IgG or anti-AQP4 antibody has been proposed as one of the diagnostic criteria for NMO. ${ }^{[5,81]}$

The pathological hallmark of NMO lesions is loss of the immunostaining for AQP4 and glial fibrillary acidic protein (GFAP); both are not lost in MS lesions unless there is a chronic inactive lesion or cavity. ${ }^{[82-84]}$ The pathogenic potential of anti-AQP4 antibody was demonstrated by animal models showing that transfer of human anti-AQP4 antibody into mice or rats could induce lesions typical for $\mathrm{NMO}^{[85-87]}$ with complement-dependent cytotoxicity or antibody-dependent cellular cytotoxicity as the major mechanism in the formation the NMO lesions. Currently, the presence of NMO-IgG or anti-AQP4 antibody has been one of the NMO diagnostic criteria since 2006. A spectrum of NMO disorders (NMOSD) has been formulated comprising conditions characterized by the presence of the antibody and recurrent or simultaneous bilateral $\mathrm{ON}$, and idiopathic long extensive transverse myelitis. ${ }^{[88,89]}$

There have been a variety of immunoassays used to detect anti-AQP4 antibody with high diagnostic specificity for NMO (85-100\%), although the sensitivity is moderate $(33-91 \%) .{ }^{[90,91]}$ Current immunoassays include cell-, tissue-, and protein-based assays. ${ }^{[00,92]}$ Of these three immunoassays, the cell-based assay, using cell lines that have been transfected with AQP4 protein, has been shown to be the most sensitive. ${ }^{[77,91]}$ There are two isoforms of AQP4 used for immunoassays: M1 isoform [protein generated by mRNA translation initiated at methionine (Met)-1] and M23 isoform (translation initiated at Met-23) ${ }^{[93]}$ Anti-NMO-IgG generally binds with greater affinity to M23-AQP4 than to M1-AQP4, ${ }^{[94]}$ and AQP4-M23 transfected cell-based assay seems to be slightly more sensitive than M1-based assay. ${ }^{[95-97]}$ However, the function of M1- and M23-AQP4 and in vivo conformational epitopes of AQP4 in the human CNS still needs to be elucidated. ${ }^{[33,98-100]}$

Several lines of evidence argue for a pathogenic role for anti-AQP4-IgG in NMO. First, the serum anti-AQP4-IgG was reported to be positive in blood donated 10 years before the disease onset in a 34-year-old female with NMO ${ }^{[101]}$ Second, adults with acute myelitis with less than three vertebral segments, isolated recurrent brainstem demyelination, or monophasic ON who do not fulfil the clinical criteria for NMO or NMOSD have been shown to have seropositivity of anti-AQP4-IgG at low titers. ${ }^{[102]}$ Third, positive findings in repeated antibody tests do not always predict relapses. ${ }^{[103]}$

In pediatric NMO patients, the presence of NMO-IgG or anti-AQP4 antibody can help diagnose the disease, especially in those with disease onset before the age of 10 years ${ }^{[55]}$ The seropositivity seemed to be more frequent in the patients with a relapsing course than children with a monophasic disease. ${ }^{[21,73,104]}$ In practice, the presence of NMO-IgG and anti-AQP4-IgG can help differentiate chil- 
dren with NMO and NMOSD from ADEM, CIS, and MS. Although the role of long-term antibody titer monitoring is not known, a rising level of NMO-IgG in an individual patient may predict a new attack. ${ }^{[105]}$

\section{Anti-MOG antibody}

Another biomarker is the presence of antibodies against MOG, an autoantigen expressed exclusively in the outer sheath of CNS myelin and oligodendrocytes. ${ }^{[106]}$ Although its pathogenic role is still elusive, some evidence shows that the IgG to native MOG at high titers is capable of inducing complement activation ${ }^{[107]}$ and antibody-dependent cytotoxicity when natural killer cells are present in vitro; ${ }^{[108]}$ both mechanisms contribute to CNS demyelination. The best method to detect anti-MOG antibody is a cell-based assay detecting antibodies against native MOG in natural confirmation on the cell surface and this form has been shown to be pathogenic in vitro. ${ }^{[109]}$

The anti-MOG antibody has been consistently detected in a substantial proportion of children with ADEM (27$47 \%$ ), MS (up to $21 \%$ ), CIS (up to $36 \%$ ), AQP4-IgG-seronegative $\mathrm{NMO}$, and in recurrent $\mathrm{ON}$, but only rarely in adult MS. ${ }^{[107,108,110-114]}$ Among these pediatric patients, the antibodies have been found to be transiently elevated during acute episodes. In ADEM, the level would generally decrease to an undetectable level in fully recovered patients. ${ }^{[110]}$ In patients with recurrent ON or MS, the titer was persistently detectable for up to 5 years, but usually at low titers. ${ }^{[110,112,115]}$ The persistent seropositivity of anti-MOG antibody may highlight the risk of ongoing inflammation, suggesting chronicity rather than an acute single episode of demyelination; so, these patients may warrant more aggressive treatment. ${ }^{[116]}$

\section{Brain biopsy}

Although rarely required, biopsies are occasionally performed to exclude other treatable diseases (most often tumors, ${ }^{[17]}$ vasculitis, and encephalitis) and to establish the diagnosis of demyelinating disease. ${ }^{[118]}$ The pathological study of pediatric MS and related disorders has derived mainly from atypical presentations with space-occupying lesions, fulminant illness, or fatalities. The pathology of MS is consistent with focal demyelinated plaques with various degrees of perivascular inflammation and axonal injury or loss. ${ }^{[119,120]}$ In the cortex, subpial inflammatory demyelinated lesions are typical of the progressive stages of MS, although they can also be found in the early stages. ${ }^{[121]}$

\section{Conclusion}

The updated criteria simplify the diagnosis of pediatric MS, especially for those who have a first episode of acute CNS inflammatory demyelination at age 12 years and older. The formal diagnosis of MS should always take into con- sideration the clinical, imaging, and paraclinical evidence. When there is diagnostic uncertainty, serum biomarkers may prove very valuable in the clinical diagnosis. Currently useful biomarkers include the specific NMO marker anti-AQP4 antibody and the neuroinflammatory signature anti-MOG antibody. Both may help in clinical diagnosis and treatment decision making.

\section{Acknowledgment}

We gratefully acknowledge the financial support from the Chang Gung Memorial Hospital (Research Grant CMRPG4A0122), Taoyuan, Taiwan.

\section{REFERENCES}

1. Trapp BD, Nave KA. Multiple sclerosis: An immune or neurodegenerative disorder? Annu Rev Neurosci 2008;31:247-69.

2. Renoux C, Vukusic S, Mikaeloff Y, Edan G, Clanet M, Dubois B, et al. Natural history of multiple sclerosis with childhood onset. N Engl J Med 2007;356:2603-13.

3. Harding KE, Liang $\mathrm{K}$, Cossburn MD, Ingram G, Hirst CL, Pickersgill TP, et al. Long-term outcome of paediatric-onset multiple sclerosis: A population-based study. J Neurol Neurosurg Psychiatry 2013;84:141-7.

4. Ghezzi A, Deplano V, Faroni J, Grasso MG, Liguori M, Marrosu G, et al. Multiple sclerosis in childhood: Clinical features of 149 cases. Mult Scler 1997;3:43-6.

5. Thompson AJ, Polman CH, Miller DH, McDonald WI, Brochet B, Filippi MM, et al. Primary progressive multiple sclerosis. Brain 1997;120:1085-96.

6. Duquette P, Murray TJ, Pleines J, Ebers GC, Sadovnick D, Weldon P, et al. Multiple sclerosis in childhood: Clinical profile in 125 patients. J Pediatr 1987;111:359-63.

7. Gorman MP, Healy BC, Polgar-Turcsanyi M, Chitnis T. Increased relapse rate in pediatric-onset compared with adult-onset multiple sclerosis. Arch Neurol 2009;66:54-9.

8. Yeh EA, Weinstock-Guttman B, Ramanathan M, Ramasamy DP, Willis L, Cox JL, et al. Magnetic resonance imaging characteristics of children and adults with paediatric-onset multiple sclerosis. Brain 2009;132:3392-400.

9. Julian L, Serafin D, Charvet L, Ackerson J, Benedict R, Braaten E, et al. Cognitive impairment occurs in children and adolescents with multiple sclerosis: Results from a United States network. J Child Neurol 2013;28:102-7.

10. Weisbrot D, Charvet L, Serafin D, Milazzo M, Preston T, Cleary R, et al. Psychiatric diagnoses and cognitive impairment in pediatric multiple sclerosis. Mult Scler 2014;20:588-93.

11. Chitnis T, Tenembaum S, Banwell B, Krupp L, Pohl D, Rostasy K, et al. Consensus statement: Evaluation of new and existing therapeutics for pediatric multiple sclerosis. Mult Scler 2012;18:116-27.

12. Huppke P, Stark W, Zurcher C, Huppke B, Bruck W, Gartner J. Natalizumab use in pediatric multiple sclerosis. Arch Neurol 2008;65:1655-8.

13. Kornek B, Aboul-Enein F, Rostasy K, Milos RI, Steiner I, Penzien J, 
et al. Natalizumab therapy for highly active pediatric multiple sclerosis. JAMA Neurol 2013;70:469-75.

14. Ghezzi A, Pozzilli C, Grimaldi LM, Moiola L, Brescia-Morra V, Lugaresi A, et al. Natalizumab in pediatric multiple sclerosis: Results of a cohort of 55 cases. Mult Scler 2013;19:1106-12.

15. Arnal-Garcia C, Garcia-Montero MR, Malaga I, Millan-Pascual J, Oliva-Nacarino P, Ramio-Torrenta L, et al. Natalizumab use in pediatric patients with relapsing-remitting multiple sclerosis. Eur J Paediatr Neurol 2013;17:50-4.

16. Makhani N, Gorman MP, Branson HM, Stazzone L, Banwell BL, Chitnis T. Cyclophosphamide therapy in pediatric multiple sclerosis. Neurology 2009;72:2076-82

17. Trebst C, Jarius S, Berthele A, Paul F, Schippling S, Wildemann B, et al. Update on the diagnosis and treatment of neuromyelitis optica: Recommendations of the Neuromyelitis Optica Study Group (NEMOS). J Neurol 2014;261:1-16.

18. Costanzi C, Matiello M, Lucchinetti CF, Weinshenker BG, Pittock SJ Mandrekar J, et al. Azathioprine: Tolerability, efficacy, and predictors of benefit in neuromyelitis optica. Neurology 2011;77:659-66.

19. Bichuetti DB, Lobato de Oliveira EM, Oliveira DM, Amorin de Souza N, Gabbai AA. Neuromyelitis optica treatment: Analysis of 36 patients. Arch Neurol 2010;67:1131-6.

20. Mealy MA, Wingerchuk DM, Palace J, Greenberg BM, Levy M. Comparison of relapse and treatment failure rates among patients with neuromyelitis optica: Multicenter study of treatment efficacy. JAMA Neurol 2014;71:324-30.

21. Tillema JM, McKeon A. The spectrum of neuromyelitis optica (NMO) in childhood. J Child Neurol 2012;27:1437-47.

22. Jacob A, Weinshenker BG, Violich I, McLinskey N, Krupp L, Fox RJ, et al. Treatment of neuromyelitis optica with rituximab: Retrospective analysis of 25 patients. Arch Neurol 2008;65:1443-8.

23. Kim SH, Kim W, Li XF, Jung IJ, Kim HJ. Repeated treatment with rituximab based on the assessment of peripheral circulating memory $\mathrm{B}$ cells in patients with relapsing neuromyelitis optica over 2 years. Arch Neurol 2011;68:1412-20.

24. Kim SH, Huh SY, Lee SJ, Joung A, Kim HJ. A 5-year follow-up of rituximab treatment in patients with neuromyelitis optica spectrum disorder. JAMA Neurol 2013;70:1110-7.

25. Palace J, Leite MI, Nairne A, Vincent A. Interferon Beta treatment in neuromyelitis optica: Increase in relapses and aquaporin 4 antibody titers. Arch Neurol 2010;67:1016-7.

26. Shimizu J, Hatanaka Y, Hasegawa M, Iwata A, Sugimoto I, Date H, et al. IFNbeta-1b may severely exacerbate Japanese optic-spinal MS in neuromyelitis optica spectrum. Neurology 2010;75:1423-7.

27. Krupp LB, Tardieu M, Amato MP, Banwell B, Chitnis T, Dale RC, et al. International pediatric multiple sclerosis study group criteria for pediatric multiple sclerosis and immune-mediated central nervous system demyelinating disorders: Revisions to the 2007 definitions. Mult Scler 2013;19:1261-7.

28. Orton SM, Morris AP, Herrera BM, Ramagopalan SV, Lincoln MR, Chao MJ, et al. Evidence for genetic regulation of vitamin D status in twins with multiple sclerosis. Am J Clin Nutr 2008;88:441-7.

29. Manouchehrinia A, Tench CR, Maxted J, Bibani RH, Britton J, Constantinescu CS. Tobacco smoking and disability progression in multiple sclerosis: United Kingdom cohort study. Brain 2013;136:2298-304
30. Ascherio A, Munger KL, Lunemann JD. The initiation and prevention of multiple sclerosis. Nat Rev Neurol 2012;8:602-12.

31. Mikaeloff Y, Caridade G, Tardieu M, Suissa S. Parental smoking at home and the risk of childhood-onset multiple sclerosis in children. Brain 2007;130:2589-95.

32. Banwell B, Bar-Or A, Arnold DL, Sadovnick D, Narayanan S, McGowan M, et al. Clinical, environmental, and genetic determinants of multiple sclerosis in children with acute demyelination: A prospective national cohort study. Lancet Neurol 2011;10:436-45.

33. Banwell B, Kennedy J, Sadovnick D, Arnold DL, Magalhaes S, Wambera K, et al. Incidence of acquired demyelination of the CNS in Canadian children. Neurology 2009;72:232-9.

34. Langer-Gould A, Zhang JL, Chung J, Yeung Y, Waubant E, Yao J. Incidence of acquired CNS demyelinating syndromes in a multiethnic cohort of children. Neurology 2011;77:1143-8.

35. Absoud M, Lim MJ, Chong WK, De Goede CG, Foster K, Gunny R, et al. Paediatric acquired demyelinating syndromes: Incidence, clinical and magnetic resonance imaging features. Mult Scler 2013; 19:76-86

36. Ketelslegers IA, Catsman-Berrevoets CE, Neuteboom RF, Boon M, van Dijk KG, Eikelenboom MJ, et al. Incidence of acquired demyelinating syndromes of the CNS in Dutch children: A nationwide study. J Neurol 2012;259:1929-35.

37. Mikaeloff Y, Adamsbaum C, Husson B, Vallee L, Ponsot G, Confavreux $\mathrm{C}$, et al. MRI prognostic factors for relapse after acute CNS inflammatory demyelination in childhood. Brain 2004;127:1942-7.

38. Banwell B, Ghezzi A, Bar-Or A, Mikaeloff Y, Tardieu M. Multiple sclerosis in children: Clinical diagnosis, therapeutic strategies, and future directions. Lancet Neurol 2007;6:887-902.

39. Mar S, Lenox J, Benzinger T, Brown S, Noetzel M. Long-term prognosis of pediatric patients with relapsing acute disseminated encephalomyelitis. J Child Neurol 2010;25:681-8.

40. Mikaeloff Y, Caridade G, Husson B, Suissa S, Tardieu M; Neuropediatric KSGotFNS. Acute disseminated encephalomyelitis cohort study: Prognostic factors for relapse. Eur J Paediatr Neurol 2007;11:90-5

41. Lucchinetti CF, Kiers L, O’Duffy A, Gomez MR, Cross S, Leavitt JA, et al. Risk factors for developing multiple sclerosis after childhood optic neuritis. Neurology 1997;49:1413-8.

42. Simone IL, Carrara D, Tortorella C, Liguori M, Lepore V, Pellegrini F, et al. Course and prognosis in early-onset MS: Comparison with adult-onset forms. Neurology 2002;59:1922-8.

43. Krupp LB, Banwell B, Tenembaum S; International Pediatric MSSG. Consensus definitions proposed for pediatric multiple sclerosis and related disorders. Neurology 2007;68 (16 Suppl 2):S7-12.

44. Polman $\mathrm{CH}$, Reingold SC, Banwell B, Clanet M, Cohen JA, Filippi M, et al. Diagnostic criteria for multiple sclerosis: 2010 revisions to the McDonald criteria. Ann Neurol 2011;69:292-302.

45. O’Mahony J, Bar-Or A, Arnold DL, Sadovnick AD, Marrie RA, Banwell B, et al. Masquerades of acquired demyelination in children: Experiences of a national demyelinating disease program. J Child Neurol 2013;28:184-97.

46. Schiffmann R, van der Knaap MS. Invited article: An MRI-based approach to the diagnosis of white matter disorders. Neurology 2009;72:750-9. 
47. Ghezzi A. Clinical characteristics of multiple sclerosis with early onset. Neurol Sci 2004;25 Suppl 4:S336-9.

48. Wilejto M, Shroff M, Buncic JR, Kennedy J, Goia C, Banwell B. The clinical features, MRI findings, and outcome of optic neuritis in children. Neurology 2006;67:258-62.

49. Banwell B, Krupp L, Kennedy J, Tellier R, Tenembaum S, Ness J, et al. Clinical features and viral serologies in children with multiple sclerosis: A multinational observational study. Lancet Neurol 2007;6:773-81.

50. Miller DH, Chard DT, Ciccarelli O. Clinically isolated syndromes. Lancet Neurol 2012;11:157-69.

51. Miller D, Barkhof F, Montalban X, Thompson A, Filippi M. Clinically isolated syndromes suggestive of multiple sclerosis, part I: Natural history, pathogenesis, diagnosis, and prognosis. Lancet Neurol $2005 ; 4: 281-8$

52. Poser CM, Paty DW, Scheinberg L, McDonald WI, Davis FA, Ebers GC, et al. New diagnostic criteria for multiple sclerosis: Guidelines for research protocols. Ann Neurol 1983;13:227-31.

53. Swanton JK, Rovira A, Tintore M, Altmann DR, Barkhof F, Filippi M, et al. MRI criteria for multiple sclerosis in patients presenting with clinically isolated syndromes: A multicentre retrospective study. Lancet Neurol 2007;6:677-86.

54. Wingerchuk DM, Lennon VA, Pittock SJ, Lucchinetti CF, Weinshenker BG. Revised diagnostic criteria for neuromyelitis optica. Neurology 2006;66:1485-9.

55. Lotze TE, Northrop JL, Hutton GJ, Ross B, Schiffman JS, Hunter JV. Spectrum of pediatric neuromyelitis optica. Pediatrics 2008;122:e1039-47.

56. Liao MF, Huang CC, Lyu RK, Chen CM, Chang HS, Chu CC, et al. Acute disseminated encephalomyelitis that meets modified McDonald criteria for dissemination in space is associated with a high probability of conversion to multiple sclerosis in Taiwanese patients. Eur J Neurol 2011;18:252-9.

57. Stonehouse M, Gupte G, Wassmer E, Whitehouse WP. Acute disseminated encephalomyelitis: Recognition in the hands of general paediatricians. Arch Dis Child 2003;88:122-4.

58. Matthews L, Marasco R, Jenkinson M, Kuker W, Luppe S, Leite MI, et al. Distinction of seropositive NMO spectrum disorder and MS brain lesion distribution. Neurology 2013;80:1330-7.

59. Callen DJ, Shroff MM, Branson HM, Li DK, Lotze T, Stephens D, et al. Role of MRI in the differentiation of ADEM from MS in children. Neurology 2009;72:968-73.

60. Verhey LH, Branson HM, Shroff MM, Callen DJ, Sled JG, Narayanan S, et al. MRI parameters for prediction of multiple sclerosis diagnosis in children with acute CNS demyelination: A prospective national cohort study. Lancet Neurol 2011;10:1065-73.

61. Patrucco L, Rojas JI, Cristiano E. Assessing the value of spinal cord lesions in predicting development of multiple sclerosis in patients with clinically isolated syndromes. J Neurol 2012;259:1317-20.

62. Bot JC, Barkhof F, Polman CH, Lycklama a Nijeholt GJ, de Groot V, Bergers E, et al. Spinal cord abnormalities in recently diagnosed MS patients: Added value of spinal MRI examination. Neurology 2004;62:226-33

63. Verhey LH, Branson HM, Makhija M, Shroff M, Banwell B. Magnetic resonance imaging features of the spinal cord in pediatric multiple sclerosis: A preliminary study. Neuroradiology 2010;52:1153-62.
64. Absoud M, Lim MJ, Chong WK, De Goede CG, Foster K, Gunny R, et al. Paediatric acquired demyelinating syndromes: Incidence, clinical and magnetic resonance imaging features. Mult Scler 2013; 19:76-86

65. Pittock SJ, Weinshenker BG, Lucchinetti CF, Wingerchuk DM, Corboy JR, Lennon VA. Neuromyelitis optica brain lesions localized at sites of high aquaporin 4 expression. Arch Neurol 2006;63:964-8.

66. Misu T, Fujihara K, Nakashima I, Sato S, Itoyama Y. Intractable hiccup and nausea with periaqueductal lesions in neuromyelitis optica. Neurology 2005;65:1479-82.

67. Link H, Huang YM. Oligoclonal bands in multiple sclerosis cerebrospinal fluid: An update on methodology and clinical usefulness. J Neuroimmunol 2006;180:17-28.

68. Freedman MS, Thompson EJ, Deisenhammer F, Giovannoni G, Grimsley G, Keir G, et al. Recommended standard of cerebrospinal fluid analysis in the diagnosis of multiple sclerosis: A consensus statement. Arch Neurol 2005;62:865-70.

69. Heussinger N, Kontopantelis E, Rompel O, Paulides M, Trollmann R. Predicting multiple sclerosis following isolated optic neuritis in children. Eur J Neurol 2013;20:1292-6.

70. Dale RC, de Sousa C, Chong WK, Cox TC, Harding B, Neville BG Acute disseminated encephalomyelitis, multiphasic disseminated encephalomyelitis and multiple sclerosis in children. Brain 2000;123 Pt 12:2407-22.

71. Hung PC, Wang HS, Chou ML, Lin KL, Hsieh MY, Wong AM. Acute disseminated encephalomyelitis in children: A single institution experience of 28 patients. Neuropediatrics 2012;43:64-71.

72. de Seze J, Lebrun C, Stojkovic T, Ferriby D, Chatel M, Vermersch P. Is Devic's neuromyelitis optica a separate disease? A comparative study with multiple sclerosis. Mult Scler 2003;9:521-5.

73. McKeon A, Lennon VA, Lotze T, Tenenbaum S, Ness JM, Rensel M, et al. CNS aquaporin-4 autoimmunity in children. Neurology 2008;71:93-100.

74. Cheng C, Jiang Y, Chen X, Dai Y, Kang Z, Lu Z, et al. Clinical, radiographic characteristics and immunomodulating changes in neuromyelitis optica with extensive brain lesions. BMC Neurol $2013 ; 13: 72$

75. Wingerchuk DM, Hogancamp WF, O'Brien PC, Weinshenker BG The clinical course of neuromyelitis optica (Devic's syndrome). Neurology 1999;53:1107-14.

76. Lennon VA, Wingerchuk DM, Kryzer TJ, Pittock SJ, Lucchinetti CF, Fujihara K, et al. A serum autoantibody marker of neuromyelitis optica: Distinction from multiple sclerosis. Lancet 2004;364:2106-12

77. Lennon VA, Kryzer TJ, Pittock SJ, Verkman AS, Hinson SR. IgG marker of optic-spinal multiple sclerosis binds to the aquaporin-4 water channel. J Exp Med 2005;202:473-7.

78. Jarius S, Wildemann B. AQP4 antibodies in neuromyelitis optica: Diagnostic and pathogenetic relevance. Nat Rev Neurol 2010;6:383-92

79. Amiry-Moghaddam M, Ottersen OP. The molecular basis of water transport in the brain. Nat Rev Neurosci 2003;4:991-1001.

80. Nielsen S, Nagelhus EA, Amiry-Moghaddam M, Bourque C, Agre P, Ottersen OP. Specialized membrane domains for water transport in glial cells: High-resolution immunogold cytochemistry of aquaporin-4 in rat brain. J Neurosci 1997;17:171-80. 
81. Miller DH, Weinshenker BG, Filippi M, Banwell BL, Cohen JA, Freedman MS, et al. Differential diagnosis of suspected multiple sclerosis: A consensus approach. Mult Scler 2008;14:1157-74.

82. Roemer SF, Parisi JE, Lennon VA, Benarroch EE, Lassmann H, Bruck W, et al. Pattern-specific loss of aquaporin-4 immunoreactivity distinguishes neuromyelitis optica from multiple sclerosis. Brain 2007;130:1194-205

83. Lucchinetti CF, Mandler RN, McGavern D, Bruck W, Gleich G, RansohoffRM, et al. Arole for humoral mechanisms in the pathogenesis of Devic's neuromyelitis optica. Brain 2002;125:1450-61.

84. Misu T, Fujihara K, Kakita A, Konno H, Nakamura M, Watanabe S, et al. Loss of aquaporin 4 in lesions of neuromyelitis optica: Distinction from multiple sclerosis. Brain 2007;130:1224-34.

85. Bennett JL, Lam C, Kalluri SR, Saikali P, Bautista K, Dupree C, et al. Intrathecal pathogenic anti-aquaporin-4 antibodies in early neuromyelitis optica. Ann Neurol 2009;66:617-29.

86. Saadoun S, Waters P, Bell BA, Vincent A, Verkman AS, Papadopoulos MC. Intra-cerebral injection of neuromyelitis optica immunoglobulin $\mathrm{G}$ and human complement produces neuromyelitis optica lesions in mice. Brain 2010;133:349-61.

87. Asavapanumas N, Ratelade J, Verkman AS. Unique neuromyelitis optica pathology produced in naive rats by intracerebral administration of NMO-IgG. Acta Neuropathol 2014;127:539-51.

88. Wingerchuk DM, Lennon VA, Lucchinetti CF, Pittock SJ, Weinshenker BG. The spectrum of neuromyelitis optica. Lancet Neurol 2007;6:805-15.

89. Sellner J, Boggild M, Clanet M, Hintzen RQ, Illes Z, Montalban X, et al. EFNS guidelines on diagnosis and management of neuromyelitis optica. Eur J Neurol 2010;17:1019-32.

90. Jarius S, Wildemann B. Aquaporin-4 antibodies (NMO-IgG) as a serological marker of neuromyelitis optica: A critical review of the literature. Brain Pathol 2013;23:661-83.

91. Waters PJ, McKeon A, Leite MI, Rajasekharan S, Lennon VA, Villalobos A, et al. Serologic diagnosis of NMO: A multicenter comparison of aquaporin-4-IgG assays. Neurology 2012;78:665-71.

92. Waters P, Vincent A. Detection of anti-aquaporin-4 antibodies in neuromyelitis optica: Current status of the assays. Int MS J 2008;15:99-105.

93. Ratelade J, Verkman AS. Neuromyelitis optica: Aquaporin-4 based pathogenesis mechanisms and new therapies. Int $\mathrm{J}$ Biochem Cell Biol 2012;44:1519-30.

94. Crane JM, Lam C, Rossi A, Gupta T, Bennett JL, Verkman AS. Binding affinity and specificity of neuromyelitis optica autoantibodies to aquaporin-4 M1/M23 isoforms and orthogonal arrays. Int J Biochem Cell Biol 2011;286:16516-24.

95. Pisani F, Sparaneo A, Tortorella C, Ruggieri M, Trojano M, Mola MG, et al. Aquaporin-4 autoantibodies in Neuromyelitis Optica: AQP4 isoform-dependent sensitivity and specificity. PLoS One 2013;8:e79185.

96. Mader S, Lutterotti A, Di Pauli F, Kuenz B, Schanda K, Aboul-Enein F, et al. Patterns of antibody binding to aquaporin-4 isoforms in neuromyelitis optica. PLoS One 2010;5:e10455.

97. Marignier R, Bernard-Valnet R, Giraudon P, Collongues N, Papeix C, Zephir $\mathrm{H}$, et al. Aquaporin-4 antibody-negative neuromyelitis optica: Distinct assay sensitivity-dependent entity. Neurology
2013;80:2194-200.

98. Rossi A, Ratelade J, Papadopoulos MC, Bennett JL, Verkman AS. Neuromyelitis optica IgG does not alter aquaporin-4 water permeability, plasma membrane M1/M23 isoform content, or supramolecular assembly. Glia 2012;60:2027-39.

99. Rossi A, Moritz TJ, Ratelade J, Verkman AS. Super-resolution imaging of aquaporin-4 orthogonal arrays of particles in cell membranes. J Cell Sci 2012;125:4405-12.

100. Verkman AS, Phuan PW, Asavapanumas N, Tradtrantip L. Biology of AQP4 and anti-AQP4 antibody: Therapeutic implications for NMO. Brain Pathol 2013;23:684-95.

101. Nishiyama S, Ito T, Misu T, Takahashi T, Kikuchi A, Suzuki N, et al. A case of NMO seropositive for aquaporin-4 antibody more than 10 years before onset. Neurology 2009;72:1960-1.

102. Sato DK, Nakashima I, Takahashi T, Misu T, Waters P, Kuroda H, et al. Aquaporin-4 antibody-positive cases beyond current diagnostic criteria for NMO spectrum disorders. Neurology 2013;80:2210-6.

103. Chanson JB, Alame M, Collongues N, Blanc F, Fleury M, Rudolf $\mathrm{G}$, et al. Evaluation of clinical interest of anti-aquaporin-4 autoantibody followup in neuromyelitis optica. Clin Dev Immunol $2013 ; 2013: 146219$

104. Banwell B, Tenembaum S, Lennon VA, Ursell E, Kennedy J, Bar-Or A, et al. Neuromyelitis optica-IgG in childhood inflammatory demyelinating CNS disorders. Neurology 2008;70:344-52.

105. Jarius S, Aboul-Enein F, Waters P, Kuenz B, Hauser A, Berger T, et al. Antibody to aquaporin-4 in the long-term course of neuromyelitis optica. Brain 2008;131:3072-80.

106. Linington C, Bradl M, Lassmann H, Brunner C, Vass K. Augmentation of demyelination in rat acute allergic encephalomyelitis by circulating mouse monoclonal antibodies directed against a myelin/ oligodendrocyte glycoprotein. Am J Pathol 1988;130:443-54.

107. Mader S, Gredler V, Schanda K, Rostasy K, Dujmovic I, Pfaller K, et al. Complement activating antibodies to myelin oligodendrocyte glycoprotein in neuromyelitis optica and related disorders. J Neuroinflammation 2011;8:184.

108. Brilot F, Dale RC, Selter RC, Grummel V, Kalluri SR, Aslam M, et al. Antibodies to native myelin oligodendrocyte glycoprotein in children with inflammatory demyelinating central nervous system disease. Ann Neurol 2009;66:833-42.

109. Zhou D, Srivastava R, Nessler S, Grummel V, Sommer N, Bruck W, et al. Identification of a pathogenic antibody response to native myelin oligodendrocyte glycoprotein in multiple sclerosis. Proc Natl Acad Sci U S A 2006;103:19057-62.

110. Di Pauli F, Mader S, Rostasy K, Schanda K, Bajer-Kornek B, Ehling R, et al. Temporal dynamics of anti-MOG antibodies in CNS demyelinating diseases. Clin Immunol 2011;138:247-54.

111. McLaughlin KA, Chitnis T, Newcombe J, Franz B, Kennedy J, McArdel S, et al. Age-dependent B cell autoimmunity to a myelin surface antigen in pediatric multiple sclerosis. J Immunol 2009;183:4067-76.

112. Rostasy K, Mader S, Schanda K, Huppke P, Gartner J, Kraus V, et al. Anti-myelin oligodendrocyte glycoprotein antibodies in pediatric patients with optic neuritis. Arch Neurol 2012;69:752-6.

113. Selter RC, Brilot F, Grummel V, Kraus V, Cepok S, Dale RC, et al. Antibody responses to $\mathrm{EBV}$ and native $\mathrm{MOG}$ in pediatric inflammatory demyelinating CNS diseases. Neurology 2010;74:1711-5. 
114. Lalive PH, Hausler MG, Maurey H, Mikaeloff Y, Tardieu M, Wiendl $\mathrm{H}$, et al. Highly reactive anti-myelin oligodendrocyte glycoprotein antibodies differentiate demyelinating diseases from viral encephalitis in children. Mult Scler 2011;17:297-302.

115. Rostasy K, Mader S, Hennes EM, Schanda K, Gredler V, Guenther A, et al. Persisting myelin oligodendrocyte glycoprotein antibodies in aquaporin-4 antibody negative pediatric neuromyelitis optica. Mult Scler 2013;19:1052-9.

116. Mayer MC, Breithaupt C, Reindl M, Schanda K, Rostasy K, Berger T, et al. Distinction and temporal stability of conformational epitopes on myelin oligodendrocyte glycoprotein recognized by patients with different inflammatory central nervous system diseases. J Immunol 2013;191:3594-604.

117. Mordekar SR, Rittey CD, Jaspan T, Connolly DJ, Whitehouse WP.
Glioblastoma multiforme incorrectly diagnosed as ADEM in children. J Paediatr Neurol 2008;6:53-6.

118. Kuhlmann T, Lassmann H, Bruck W. Diagnosis of inflammatory demyelination in biopsy specimens: A practical approach. Acta Neuropathol 2008;115:275-87.

119. Lucchinetti C, Bruck W, Parisi J, Scheithauer B, Rodriguez M, Lassmann H. Heterogeneity of multiple sclerosis lesions: Implications for the pathogenesis of demyelination. Ann Neurol 2000;47:707-17.

120. Trapp BD, Peterson J, Ransohoff RM, Rudick R, Mork S, Bo L. Axonal transection in the lesions of multiple sclerosis. N Engl J Med 1998;338:278-85.

121. Lucchinetti CF, Popescu BF, Bunyan RF, Moll NM, Roemer SF, Lassmann $\mathrm{H}$, et al. Inflammatory cortical demyelination in early multiple sclerosis. N Engl J Med 2011;365:2188-97. 